\title{
Life Test Approach for Refractory Metal/Sodium Heat Pipes
}

\author{
James J. Martin and Robert S. Reid \\ NASA MSFC, ER11, Huntsville, Alabama, 35812 \\ (256) 544-6054, jim.j.martin@nasa.gov \\ (256) 544-1523, robert.s.reid@nasa.gov
}

\begin{abstract}
Heat pipe life tests described in the literature have seldom been conducted on a systematic basis. Typically one or more heat pipes are built and tested for an extended period at a single temperature with simple condenser loading. This paper describes an approach to generate carefully controlled data that can conclusively establish heat pipe operating life with material-fluid combinations capable of extended operation. Approximately 10 years of operational life might be compressed into 3 years of laboratory testing through a combination of increased temperature and mass fluence. Two specific test series have been identified and include: investigation of long term corrosion rates based on the guidelines contained in ASTM G-68-80 (using 7 heat pipes); and investigation of corrosion trends in a cross correlation sequence at various temperatures and mass fluences based on a central composite test design (using 9 heat pipes). The heat pipes selected for demonstration purposes are fabricated from a Mo-44.5\% Re alloy with a length of 0.3 meters and diameter of $1.59 \mathrm{~cm}$ (to conserve material) with a condenser to evaporator length ratio of approximately 3. The wick is a crescent annular design formed from 400-mesh Mo-Re alloy material hot isostatically pressed to produce a final wick pore radius of 20 microns or less. A processing methodology has been devised that incorporates vacuum distillation filling with an integrated purity sampling technique using vanadium wire equilibration (ASTM 997-83); this provides insight into the sodium oxygen concentration in the final heat pipe assembly. To minimize the possibility for contamination through mass transfer, energy is both supplied and extracted from the heat pipe using non-contact approaches. Radio frequency induction coils couple to the evaporator with an input range of 1 to $5 \mathrm{~kW}$ per unit while a static gas gap coupled water calorimeter provides condenser cooling for heat pipe temperatures ranging from 1123 to $1323 \mathrm{~K}$. The test chamber atmosphere is subject to active purification targeting a level of $0.3 \mathrm{ppb}$ oxygen at an operating pressure of approximately 75 torr (an oxygen level comparable to a $10^{-6}$ torr vacuum environment). The test is designed to operate round-the-clock with 6-month non-destructive inspection intervals to identify the onset and level of corrosion. At longer intervals specific ASTM G-68-80 series heat pipes are destructively evaluated to verify the non-destructive observations.
\end{abstract}

\section{INTRODUCTION}

In the 1980s a group at Los Alamos National Laboratory began to approach heat pipe life testing using sciencebased methods (Lundberg, 1987). Tests were performed on various alkali metal heat pipes for extended periods at elevated temperature and power. Material examination and assay were often conducted before and after test. Techniques such as x-ray microanalysis, electron microprobe, x-ray fluorescence, and Auger-ESCA (electron spectroscopy for chemical analysis) were used in characterization. High temperature corrosion modes were proposed from forensic examination of failed and non-failed heat pipes. Attempts were made to understand complex chemical equilibrium mechanisms using free energy minimization techniques with data supplied or extrapolated from the literature. One such thermal chemical simulation of the Niobium/Potassium $(\mathrm{Nb} / \mathrm{K})$ system with typical contaminant levels found no life limiting corrosion after $7 \mathrm{yr}$ of operation at $875 \mathrm{~K}$ (Feber, 1987).

During the SP-100 program, work was also done at Los Alamos to systematically test heat pipes at several temperatures and mass fluences. Sena (1990) reported results for eight $\mathrm{K}$ filled $\mathrm{Nb}-1 \% \mathrm{Zr}$ heat pipes that were tested for 7000 to 14000 hours (h) in the $850 \mathrm{~K}$ to $950 \mathrm{~K}$ range. One of these pipes developed a small evaporator leak at $13000 \mathrm{~h}$ that did not affect the operation of the heat pipe and was not detected by the vacuum system monitor. Tests on the other heat pipes concluded with no apparent problems. It is believed that $\mathrm{Zr}$ in an $\mathrm{Nb}-1 \% \mathrm{Zr}$ centering wire of the one failed heat pipe touched the quartz tube during test. A wire-quartz contact point on the failed heat pipe surface was discovered after $13000 \mathrm{~h}$ of test. Zirconium, being more stable than quartz, partitioned oxygen (O), causing $\mathrm{O}$ to diffuse from the quartz to the condenser wall. Oxygen from the quartz appears to have migrated to the heat pipe and saturated the $\mathrm{Zr}$ in the evaporator. Conditions for these eight $\mathrm{Nb}-1 \% \mathrm{Zr} / \mathrm{K}$ heat pipe tests approximated a $3^{2}$ factorial configuration with temperature and radial heat flux to the evaporator as the two controlled factors. As far as it is known, this test was one of the first attempts to develop a multifactor response surface in a heat pipe 
corrosion test. In this case results from the partial two-level factorial test series could have identified first order effects and interactions between the two factors (Deming, 1987).

The objective of the current effort was to extend this approach by developing a systematic experimental test program to establish life-limiting issues for Molybdenum-Rhenium (Mo-Re) alloy/sodium (Na) heat pipes. To accomplish this task a series of $\mathbf{1 6}$ heat pipes are required, designed to simplify fabrication and make use of available materials minimizing overall program cost and providing rapid progress toward hardware testing. The planned test program makes use of an accelerated approach (increased temperature and mass fluence), compressing twelve years of nominal operation into three years of around the clock testing. A significant benefit of this approach is that periodic inspections (set at nominal six months intervals) provide near term experimental test data which can be compared to predicted trends validating the hardware system early in the program. The following sections provide detail regarding the test hardware and evaluation process.

\section{PROPOSED LIFE TESTING METHODOLOGY}

There are several ways to establish heat pipe material system life without a full term test. One approach is to hasten life-limiting effects; this can be accomplished, for instance, by testing at higher than the proposed operating temperature and mass fluence. Acceleration testing is intuitively appealing. The impurity corrosion rate is proportional to the accumulation of elements such as $\mathrm{O}, \mathrm{Si}$, and $\mathrm{C}$ in the heat pipe evaporator. As working fluid flows into the evaporator it vaporizes, concentrating the impurities and making the corrosion rate appear dependent on mass fluence. The radial heat flux $\left(q_{\mathrm{rad}}\right)$ applied to the evaporator is given by

$$
q_{\mathrm{rad}}=q\left(\pi d L_{\mathrm{e}}\right)^{-1},
$$

where $q$ is the applied evaporator power, $d$ is the heat pipe diameter and $L_{e}$ is the length of the evaporator section. Mass flux $(G)$ through the evaporator is a function of the radial heat flux,

$$
G=q_{\mathrm{rad}}\left(h_{\mathrm{fg}}\right)^{-1},
$$

where $h_{f g}$ is the latent heat of vaporization. Mass fluence $\left(M^{\eta}\right)$ through the evaporator is then given by

$$
M^{\prime \prime}=G \tau
$$

where $\tau$ is the operational time. Mass fluence can easily be increased by applying power along a shortened heat pipe evaporator length. Mass fluence can be used as a metric to accelerate heat pipe life or to affordably test subscale versions of a flight unit. Mass diffusion transfers impurities from the heat pipe structure to the working fluid. The Arrhenius equation relates impurity diffusion rates to heat pipe temperature. Test conditions can be normalized using the expression:

$$
\alpha(T)=\exp \left[(\Delta H / R)\left(T_{0}^{-1}-T^{-1}\right)\right]
$$

where $\Delta H$ is activation energy, $R$ is the universal gas constant, $T_{0}$ is the design temperature, and $T$ is the heat pipe test temperature. It can be argued that since testing at high temperature accelerates the Arrhenius-governed diffusion rate, this same acceleration applies to heat pipe life. Such simplistic views must be approached with caution. The nature of chemical reactions and their kinetics can change dramatically with absolute temperature. Conditions that apply at one temperature do not necessarily hold true for others. Without deeper understanding of the underlying reaction mechanisms, conclusions drawn from such tests may be misleading.

Another approach to heat pipe life prediction involves extrapolation of corrosion effects of a reference design from separate tests conducted over different durations. Corrosion or reaction metrics are taken for each test specimen, and the results are plotted versus time. Appropriate metrics include changes in fluid composition, wall and wick integrity as determined by three dimensional x-ray computed tomography, species distribution, and grain boundary condition as well as non-condensable gas production measured by residual gas analysis. For the corrosion rate, a curve can be generated with a slope that normally decreases with time. The long-term corrosion rate is extrapolated from the slope near the longest test time. This method is outlined in ASTM G 68-80. Conditions of an extrapolated test series 
can closely match those of a proposed reference. Extrapolation tests conducted at prototypic temperatures avoid possible problems with elevated temperature acceleration (Reid, 2004).

A heat pipe life test matrix is proposed for a Mo-44.5\%Re/Na material combination as a function of operating temperature and mass fluence. Impurity levels in the heat pipe wall and working fluid are to be controlled at constant values. A series of accelerated life heat pipes permits compression of life-limiting mechanisms from the mission duration to a period consistent with the schedule of a flight program. The target of the proposed test program is to compress twelve years operational life into approximately three years of actual operation. Condenser calorimetry using forced convection of a cooling fluid is necessary to achieve the target power density and operating temperatures (providing realistic boundary conditions). Tables 1 and 2 show a proposed test series consisting of 16 short heat pipes: nine of these units constitute a central composite test design (referred to as a Fisher or F-Series) with the remaining 7 units accounting for the ASTM G 68-80 sequence (referred to as the G-Series). One of the experiments from the extrapolation test series is used to cross correlate fluence conditions with the F-Series sequence conducted at various temperatures and fluences. Such life tests can establish and isolate corrosion trends as a function of temperature and mass fluence.

TABLE 1. Life Test Central Composite (Fisher) Test Series (F-Series).

\begin{tabular}{|c|c|c|c|c|c|c|c|c|c|c|}
\hline $\begin{array}{l}\text { Heat } \\
\text { Pipe }\end{array}$ & $\begin{array}{c}\text { Wall / Wick } \\
\text { Material / Fluid }\end{array}$ & $L_{d} L_{0}$ & $\begin{array}{l}D_{i} \\
(\mathrm{~cm})\end{array}$ & $\begin{array}{c}T \\
(K)\end{array}$ & $\alpha(T)$ & $\begin{array}{c}q \\
(W)\end{array}$ & $\begin{array}{c}\text { qrad } \\
\left(W / \mathrm{cm}^{2}\right)\end{array}$ & $\begin{array}{c}\mathrm{G} \\
\left(\mathrm{kg} / \mathrm{cm}^{2}-\mathrm{s}\right)\end{array}$ & $\begin{array}{c}\mathrm{t} \\
\text { (h) }\end{array}$ & $\begin{array}{c}\mathrm{M}^{\prime \prime} \\
\left(\mathrm{kg} / \mathrm{cm}^{2}\right)\end{array}$ \\
\hline Design & $\mathrm{Mo}-\mathrm{Re} / \mathrm{Na}$ & 2 & 1.41 & 1250 & 1.00 & 5752 & 22 & 0.059 & 105120 & 2233 \\
\hline$F(-4)$ & $\mathrm{Mo}-\mathrm{Re} / \mathrm{Na}$ & 3 & 1.41 & 1273 & 1.30 & 5000 & 226 & 0.599 & 26280 & 5669 \\
\hline$F(-3)$ & $\mathrm{Mo}-\mathrm{Re} / \mathrm{Na}$ & 3 & 1.41 & 1273 & 1.30 & 1000 & 45 & 0.120 & 26280 & 1134 \\
\hline$F(-2)$ & $\mathrm{Mo}-\mathrm{Re} / \mathrm{Na}$ & 3 & 1.41 & 1373 & 3.74 & 3000 & 136 & 0.368 & 26280 & 3483 \\
\hline$F(-1)$ & $\mathrm{Mo}-\mathrm{Re} / \mathrm{Na}$ & 3 & 1.41 & 1173 & 0.38 & 3000 & 136 & 0.351 & 26280 & 3321 \\
\hline$F(0)$ & $\mathrm{Mo}-\mathrm{Re} / \mathrm{Na}$ & 3 & 1.41 & 1273 & 1.30 & 3000 & 136 & 0.360 & 26280 & 3401 \\
\hline$F(1)$ & $\mathrm{Mo}-\mathrm{Re} / \mathrm{Na}$ & 3 & 1.41 & 1223 & 0.72 & 2000 & 90 & 0.237 & 26280 & 2241 \\
\hline$F(2)$ & Mo-Re / Na & 3 & 1.41 & 1223 & 0.72 & 4000 & 181 & 0.474 & 26280 & 4481 \\
\hline$F(3)$ & $\mathrm{Mo}-\mathrm{Re} / \mathrm{Na}$ & 3 & 1.41 & 1323 & 2.25 & 2000 & 90 & 0.243 & 26280 & 2295 \\
\hline$F(4)$ & $\mathrm{Mo}-\mathrm{Re} / \mathrm{Na}$ & 3 & 1.41 & 1323 & 2.25 & 4000 & 181 & 0.485 & 26280 & 4589 \\
\hline
\end{tabular}

TABLE 2. Life Test ASTM G68-80 Series (G-Series).

\begin{tabular}{|c|c|c|c|c|c|c|c|c|c|c|}
\hline $\begin{array}{l}\text { Heat } \\
\text { Pipe }\end{array}$ & $\begin{array}{l}\text { Wall / Wick } \\
\text { Material / Fluid }\end{array}$ & $L_{d} / L_{n}$ & $\begin{array}{c}D_{i} \\
(\mathrm{~cm})\end{array}$ & $\begin{array}{c}T \\
(K)\end{array}$ & $\alpha(T)$ & $\begin{array}{c}q \\
(W)\end{array}$ & $\begin{array}{c}\text { qrad } \\
\left(\mathrm{W} / \mathrm{cm}^{2}\right)\end{array}$ & $\begin{array}{c}\mathrm{G} \\
\left(\mathrm{kg} / \mathrm{cm}^{2}-\mathrm{s}\right)\end{array}$ & $\begin{array}{c}t \\
\text { (h) }\end{array}$ & $\begin{array}{c}\mathrm{M}^{\prime \prime} \\
\left(\mathrm{kg} / \mathrm{cm}^{2}\right)\end{array}$ \\
\hline Design & $\mathrm{Mo}-\mathrm{Re} / \mathrm{Na}$ & 2 & 1.41 & 1250 & 1.00 & 5752 & 22 & 0.059 & 105120 & 2233 \\
\hline G-1 & $\mathrm{Mo}-\mathrm{Re} / \mathrm{Na}$ & 3 & 1.41 & 1273 & 1.30 & 3000 & 136 & 0.360 & 4380 & 567 \\
\hline G-2 & $\mathrm{Mo}-\mathrm{Re} / \mathrm{Na}$ & 3 & 1.41 & 1273 & 1.30 & 3000 & 136 & 0.360 & 8760 & 1134 \\
\hline G-3 & Mo-Re/ $\mathrm{Na}$ & 3 & 1.41 & 1273 & 1.30 & 3000 & 136 & 0.360 & 13140 & 1701 \\
\hline G-4 & $\mathrm{Mo}-\mathrm{Re} / \mathrm{Na}$ & 3 & 1.41 & 1273 & 1.30 & 3000 & 136 & 0.360 & 17520 & 2267 \\
\hline G-5 & $\mathrm{Mo}-\mathrm{Re} / \mathrm{Na}$ & 3 & 1.41 & 1273 & 1.30 & 3000 & 136 & 0.360 & 21900 & 2834 \\
\hline G-6 & $\mathrm{Mo}-\mathrm{Re} / \mathrm{Na}$ & 3 & 1.41 & 1273 & 1.30 & 3000 & 136 & 0.360 & 26280 & 3401 \\
\hline G-7 & $\mathrm{Mo}-\mathrm{Re} / \mathrm{Na}$ & 3 & 1.41 & 1273 & 1.30 & 3000 & 136 & 0.360 & 30660 & 3968 \\
\hline
\end{tabular}

\section{LIFE TEST HEAT PIPE DESCRIPTION}

The envelopes of the proposed heat pipes are fabricated from a Molybdenum- $44.5 \%$ Rhenium (Mo-44.5\%Re) alloy formed using powder metallurgy techniques (tubing and rod stock available though Rhenium Alloys Inc.). To conserve materials, the heat pipe length was limited to approximately $33 \mathrm{~cm}$ with an outside diameter of $1.58 \mathrm{~cm}$ (wall thickness of $1.27 \mathrm{~mm}$ ). The internal capillary wick was formed from Mo-5\%Re 400x400 screen mesh (existing stock from a previous NASA programs) with a wire diameter of $0.025 \mathrm{~mm}$. During wick development two techniques were examined including drawing and hot isostatic pressing (HIP'ing); sample wicks were produced with both methods (by Advanced Methods and Materials Inc.) to evaluate the process and final product. As anticipated the drawing technique was fairly simple to implement producing a highly ductile wick (formed at room temperature with no grain growth issues); however layers were only mechanically bonded and separation could easily occur. In contrast the HIP process was more complex in its implementation, however produced a final wick with diffusion bonded layers. This bonding provided excellent dimensional control of the final part while still retaining ductility; re-crystallization of the Mo-5\% Re and loss of ductility being a concern since the HIP'ing was performed at a 
temperature of approximately $1250 \mathrm{~K}$.

Table 3 shows an accelerated life heat pipe design. The heat pipe will be operated horizontally to mimic the neutral gravity conditions of space. An annular gap wick is selected for the life heat pipe because it is simple, robust, and performs well during ground testing. Properly designed short heat pipes tested at relevant temperatures and mass fluence are made geometrically similar $\left(\mathrm{L}_{\mathrm{c}} / \mathrm{L}_{\mathrm{e}}\right)$ to the flight heat pipes. Such similarity in heat pipe designs form the basis for virtually all long-term heat pipe corrosion testing to date (Lundberg, 1987). The length of the heated region is $7.5 \mathrm{~cm}$ and the cooled region is $25 \mathrm{~cm}$, reflecting approximate geometric similitude with a flight heat pipe. For the case of an annular gap wick, the channel dimension, $A$, is the concentric distance from the wick's outer and the pipe's inner surfaces. The value for $\boldsymbol{A}$ is chosen to optimize life test heat pipe performance at the reference temperature. A wick's maximum pore radius, $r$, most directly influences its capillary pumping capacity. A 45micron effective pore radius has been assumed for the life heat pipe design. Experimental bubble point testing of the HIP'ed wick element showed a 20 -micron pore radius, well within program requirements. Radial power densities applied to the evaporator, operating temperature, and nucleation site radii are key variables in boiling limit calculations. Nucleation site radii of one to three microns are typical for many engineering surfaces and will be assumed for the life heat pipe.

The HTPIPE code (Woloshun et al., 1988) predicts heat pipe performance limits as a function of evaporator exit temperature and calculates axial temperature and pressure profiles. The computational routines in HTPIPE have been validated on numerous occasions using alkali metal heat pipe test data for instance in (Dickenson, 1997), (Reid, 2002). The code uses a pressure balance in the flow direction for both the liquid and vapor to define the wicking limit or the viscous limit, depending upon whether the wick pumping capacity or the stagnation pressure defines the limiting available pressure. Other heat pipe performance limits calculated by the program are the sonic limit, the entrainment limit, and the boiling limit. Figure 1 superimposes the proposed life test matrix on a heat pipe performance map calculated with HTPIPE. Boiling limits assuming a one-micron and three-micron nucleation site radius are shown. This plot emphasizes the importance of producing heat pipes with honed heated regions.

TABLE 3. Life Heat Pipe Design and Conditions.

\begin{tabular}{ll} 
Parameter & \multicolumn{1}{c}{ Value } \\
Wick Shape & Annular Gap \\
Evaporator Length & $\mathrm{Le}=0.075 \mathrm{~m}$ \\
Adiabatic Length & $\mathrm{La}=\sim 0.00 \mathrm{~m}$ \\
Condenser Length & $\mathrm{Lc}=0.25 \mathrm{~m}$ \\
Container Inside Radius & $\mathrm{R}=0.705 \mathrm{~cm}$ \\
Channel Dimension & $\mathrm{A}=\sim 0.056 \mathrm{~cm}$ \\
Wick Pore Radius & $\mathrm{r}=35$ micron nominal \\
Nucleation Site Radius & $\mathrm{n}=\sim 1$ micron \\
Solid Thermal Conductivity & $\mathrm{k}=60 \mathrm{~W} \cdot \mathrm{m}-1 . \mathrm{K}-1$ \\
Working Fluid & $\mathrm{f}=\mathrm{Na}$ \\
Temperature & $\mathrm{T}=\{1173$ to $1373 \mathrm{~K}\}$ \\
Design Heat Pipe Power & $\mathrm{Q}=3 \mathrm{kWt}$
\end{tabular}

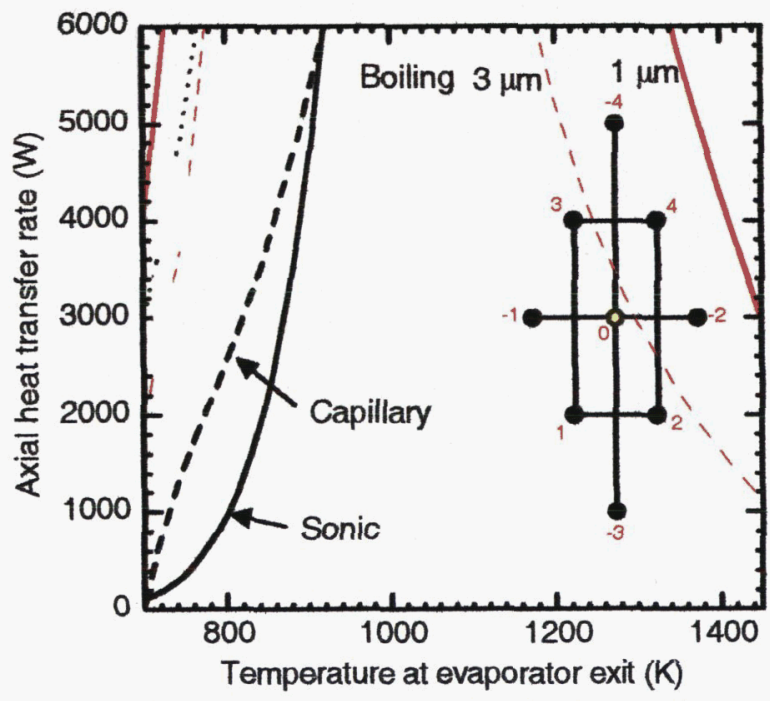

FIGURE 1. Proposed Life Test Matrix Compared to Operating Limits at Two Nucleation Site Radii.

\section{TEST HARDWARE SYSTEMS AND CONFIGURATION}

Round the clock test evaluation of the sixteen heat pipes requires a number of hardware systems to be built. Noncontact methods were selected for evaporator power deposition (radio frequency induction heating) and condenser power extraction (static gas gap coupled water cooled calorimeter). The use of a background gas (helium, argon and helium/argon mixtures) to thermally link the condenser and calorimeter requires active purification to minimize the random introduction of external contaminates to the heat pipe environment. To test the series of heat pipes a number 
of environmental test chambers containing the thermal transport systems and gas atmosphere were developed. Two types of environmental test chambers have been outlined to satisfy the test requirement. These include several large chambers, each containing a cluster of five heat pipe/calorimeter assemblies (arranged in a pentagonal configuration) and a small test chamber that contains the single high power heat pipe. The shell and flange arrangement on all chambers made use of commercial off-the-shelf vacuum rated items. In general, commonality will be maintained (to the extent possible) with respect to the designs, selection of hardware items and overall construction to allow flexibility in the final hardware setup. Figure 2 illustrates the large test chambers configuration for evaluation of 15 of the heat pipes. The following sections provide description of the primary subsystems.

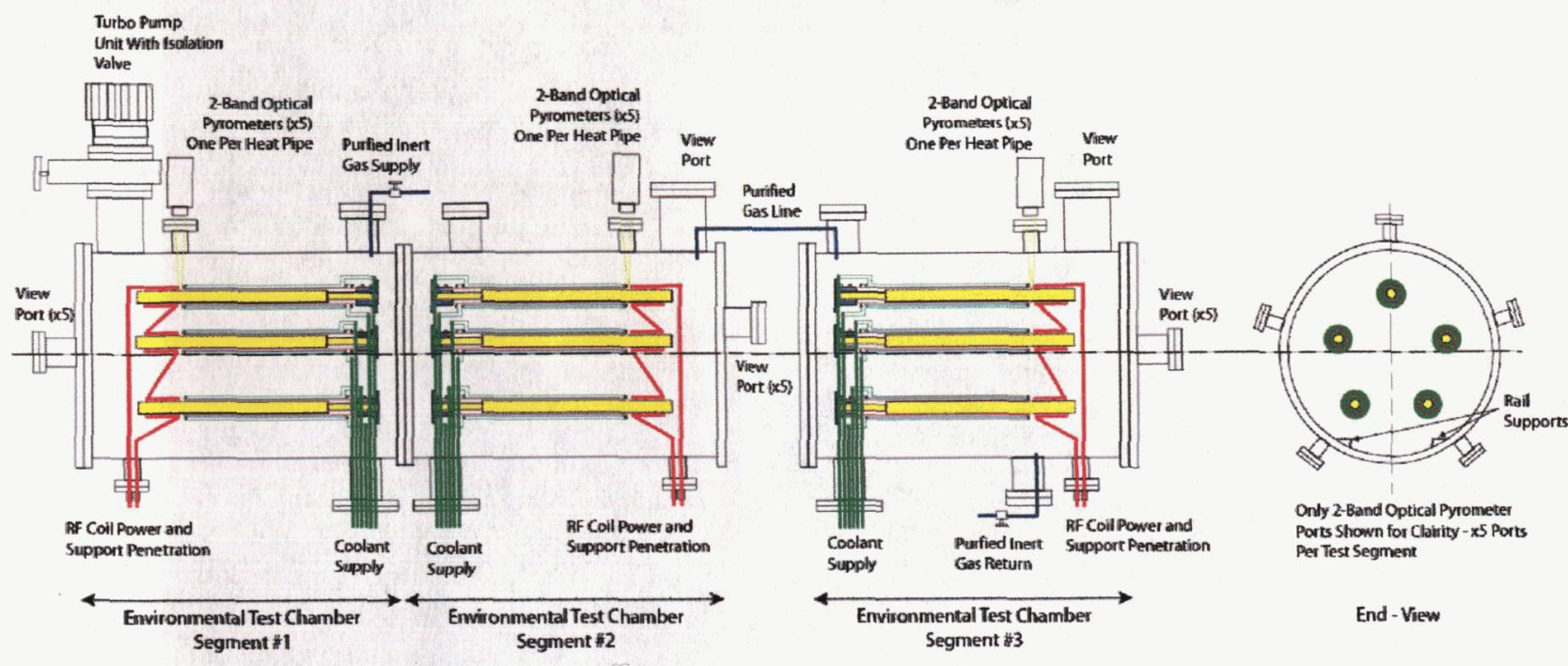

FIGURE 2. General Configuration Environmental Test Chambers.

\section{Radio Frequency Heating Subsystem}

Induction heating was selected to provide a well-characterized mass transfer boundary at the heat pipe evaporator. Fifteen of sixteen life test heat pipes are inductively heated in three clusters with each cluster containing five positions configured in a series pentagonal arrangement, Figure 3; the single high power heat pipe is inductively heated in its own test chamber. The pentagonal cross arrangement minimizes inductive interference among positions and provides an economical method to test a large number of heat pipes. Each induction coil can be affixed to or removed from its bus bar with mounting pins or screws in a flexible modular fashion. To estimate the RF system heating capability and to establish voltage, current, and frequency requirements, a quick assessment was performed using 1-D (ELTA software package by Electro-Thermal Analysis marketed by BNV Corp)and 2-D (using Flux2D software by CEDRAT Technologies) modeling software. These assessments also included the use of magnetic flux concentrators attached to the inductive coils to minimize calorimeter coupling and provide enhanced power uniformity within heat pipe evaporator. Figure 4 shows the typical efficiency of a series coil cluster as a function of power supply frequency; operation above $20 \mathrm{kHz}$ is desired. It is planned to power each of the three heat pipe clusters from independent supplies (Inductoheat Model UP16 rated to $50 \mathrm{~kW}$ at frequencies up to $50 \mathrm{kHz}$ ).

Additional considerations factored into the analysis included the potential for voltage breakdown and thermal loss from the hot heat pipe to the cold inductive coils. At the typical chamber operating pressures of 50 to 100 torr a glow discharge could potentially damage the part under test (either by sputter or direct arc impingement). To minimize the potential for voltage breakdown it is desirable to set the voltage drop between the inductive coil and the heat pipe as low as possible and the physical distance between the components as large as possible. However as the separation gap between the heat pipe surface and the inductive coil are increased, the induced coupling is adversely affected, requiring higher voltages to achieve power transfer; producing competing effects. Voltage breakdown for both direct current and RF potentials have been determined for various gases and are documented as Paschen curves (product of pressure and distance) in the literature (Weston, 1960; Park, 2001; Loeb, 1939). Based the breakdown 
information and overall RF efficiency it was found that a $6.4 \mathrm{~mm}$ inductive coil offset provides a good configuration compromise. At this setting, the series cluster inductive coils operate at a maximum of approximately $225 \mathrm{~V}$ providing a margin of 2 on the estimated Paschen minimum. As with voltage breakdown, to minimize the thermal loss (due to combined radiation and gas conduction) it is advantageous to place the inductive coil as far from the heat pipe as possible; this also carries the added benefit of further reducing the potential for voltage breakdown (increasing the product of pressure and distance). At the selected offset of $6.4 \mathrm{~mm}$ an estimated $350 \mathrm{~W}$ of heat loss per heat pipe/coil assembly was calculated, well within the make up capacity of the selected RF power supply.

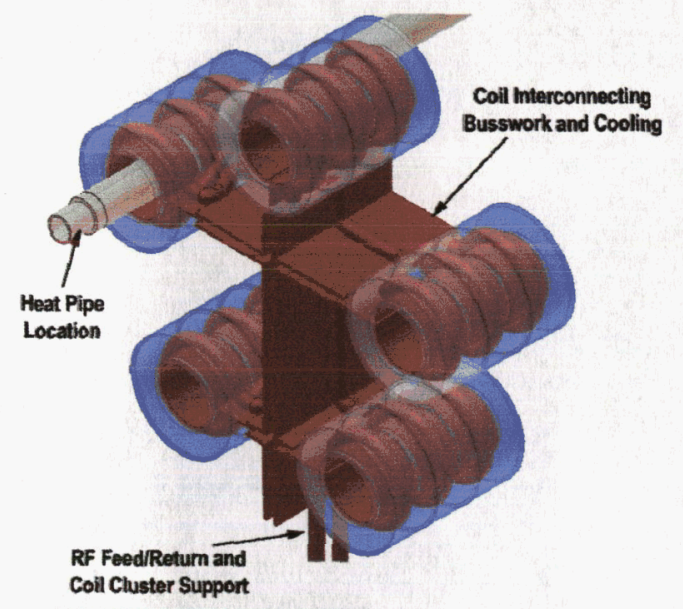

FIGURE 3. Radio Frequency Inductive Coil Assembly.

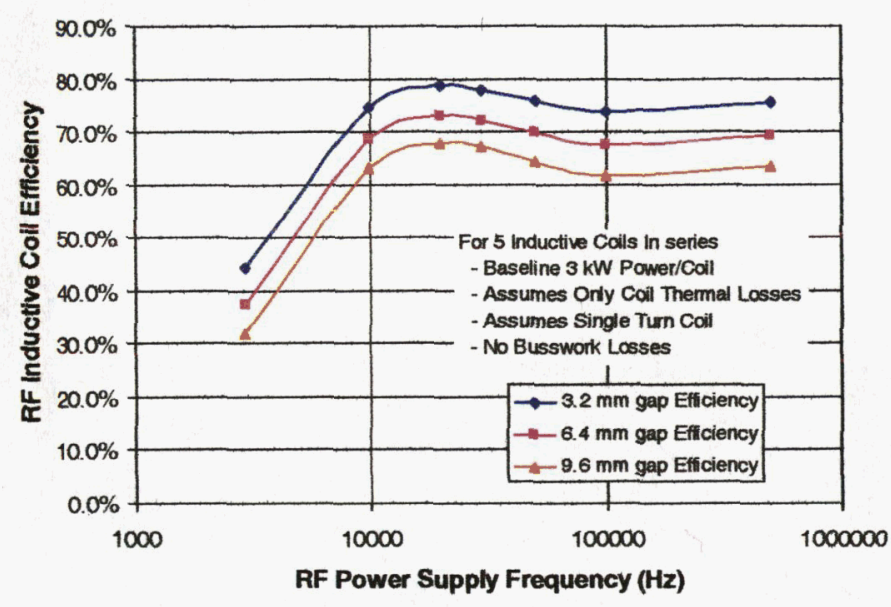

FIGURE 4. 1-D Simulation Results for Inductive Coil Efficiency.

\section{Water Cooled Calorimeter Subsystem}

To monitor heat pipe performance, a calorimetry system was devised that made use of a static gas conduction gap (between the heat pipe condenser section and the inner wall of the calorimeter) followed by a flowing water stream contained in the calorimeter annulus. The heat pipe temperature and power can be controlled by setting the width of the gas gap and gas composition (requiring specific calorimeter geometries for the outlined test matrix). Two possible methods for establishing a static gas gap include: a sealed gap requiring that the calorimeter be designed and fabricated as part of the heat pipe (a complex system) and a non-sealed gap in which the calorimeter is positioned concentric to the heat pipe and the test chamber flooded with gas (a simple system). The complexity of the sealed gap is compounded when fabricating the heat pipe units from refractory alloys. This requires that the calorimeter be fabricated from the same material and limits the types of coolant that can be used to maintain compatibility; for Mo-Re this becomes a very expensive endeavor. Use of a non-sealed/non-contact calorimeter allows the unit to be manufactured of more common materials, such as stainless steel or copper, and supported such that the heat pipe and inner diameter of the calorimeter remain nearly concentric. The selected baseline calorimeter was a copper smooth tube laminar design lending itself to simple performance estimates supporting initial concept feasibility assessment. It is comprised of three concentric tube shells referred to as the channel tube (separating the gas gap and water film annulus), shell tube (separating the water film annulus and water return annulus), and cover tube (separating the water return annulus and test chamber environment). The inlet end of the calorimeter makes use of a double wall to create an inlet plenum to distribute water to the film annulus. The cooling water passes along this annulus to the end of the calorimeter where it passes through a series of slots into the return path annulus. Tubing components for this system were selected as commercially available and are typically "off-the-shelf" items. The downside to a water based cooling system (as compared to gas) is that there is a high risk associated with the potential leakage of water into the test chamber and its potentially catastrophic interaction with refractory metals at high temperatures. To minimize this possibility, the calorimeter and all water feed lines have a welded/brazed design to avoid mechanical connections. System instrumentation includes a heat pipe evaporator exit temperature measurement just upstream of the calorimeter (using a 2-band optical pyrometer) and calorimeter water flow rate (magnetic flow meter) and inlet/outlet temperatures (thermocouples). 


\section{Test Chamber Atmosphere Subsystem}

Residual oxygen concentration is critical to the survivability of refractory metals operated at increased temperature for a relatively long time. For the proposed heat pipe testing, the refractory metal components will be operated in low-pressure, ultra high purity (UHP) noble gas environment (argon and helium mixed to a predetermined partial pressure of each gas) so that the thermal coupling between the heat pipe and calorimeter can be controlled. A generally accepted vacuum level for testing Mo-Re alloys is in the $10^{-6}$ torr range; given a direct pump down from air to $10^{-6}$ torr, the oxygen concentration is $0.28 \mathrm{ppb}$ in the vacuum test environment. Hence, the target maximum oxygen concentration in the test chambers will be $0.28 \mathrm{ppb}$ at the desired operating pressure of approximately 75 torr. To achieve the desired gas purity the initial step is to perform successive pump-downs/dilutions and component bake-out to at least $500 \mathrm{~K}$ are required to remove water and other volatiles. With this approach a level of $0.1 \mathrm{ppm}$ is achievable and is the limit based on the purity of supplied UHP bottled gases. To reduce purity level to the targeted value and maintain the test chamber environment during operations, a SAES MonoTorr Phase II 3000 point-of-use purifier with recirculation pump will be incorporated in a test chamber mounted recirculating gas loop. Within the MonoTorr purifier, getter materials are used to irreversibly trap gaseous impurity molecules; these impurities are captured on the surface of the materials and, upon heating, diffuse into the bulk of the getter. When used with argon or helium, the MonoTorr purifier can remove molecules of $\mathrm{H}_{2} \mathrm{O}, \mathrm{O}_{2}, \mathrm{H}_{2}, \mathrm{CO}, \mathrm{CO}_{2}, \mathrm{~N}_{2}$, and hydrocarbons to a level less then $0.1 \mathrm{ppb}$ (at an absolute pressure of 75 torr). For the three chamber configuration the approximate volume is 800 liters containing nearly $0.018 \mathrm{kgs}$ of helium. At a pressure of 75 torr the purifier throughput is approximately $0.023 \mathrm{~kg} / \mathrm{hr}$ resulting in approximately 1.25 gas exchanges per hour. Residual gases in a vacuum chamber derive from the original gas content of the chamber, gas emission from the chamber walls or from hardware in the chamber, or leaks from the outside of the chamber. To determine the actual gas content in the heat pipe test chambers and to assess the effectiveness of the bake-out and gas purification processes a residual gas analyzer (Dycor Dymaxion Mass Spectrometer made by Ametek Process Instruments (model DM100M)) will be employed to verify the partial pressure of various gaseous components in the test chambers throughout test.

\section{PROPOSED TESTING SEQUENCE}

Two types of tests are outlined for this project including a performance test on each heat pipe followed by the long term accelerated life testing. The initial performance test for each heat pipe is required to determine its overall capability and weed out any shortcoming that may prevent it from use in life testing (such as a reduced boiling limit). During a typical performance test the heat pipe is expected to follow the sonic limit curve during startup to a point at which the condenser coupling to the calorimeter provides the limiting thermal resistance. At this point, the heat pipe will move off the sonic limit curve and tracks across the operating envelope to a target condition at the boiling limit. When the boiling limit is reached there will be a drop in condenser power with a corresponding increase in evaporator outlet temperature, accompanied by bright spots or flashes from the heat pipe evaporator. Due to the tight wrapping of the RF inductive coil around the evaporator, visual inspection will be difficult and great care must be exercised as the boiling limit is reached. Optical observation, condenser power, and evaporator outlet temperature will be used to quantify the boiling limit during testing. Figure 5 illustrates a typical power temperature trace for a performance evaluation using the test matrix $F(-4)$ conditions with two different test chamber gas species concentration to vary the condenser/calorimeter coupling.

After a heat pipe successful completes performance testing it is ready for use in executing the accelerated life test matrix. Since the heat pipes will be tested in clusters during life test operations, a minimum of five heat pipes must be completed before initiating a life test sequence. The expected startup transient and steady state conditions are shown in Figure 6 for four of the test matrix cases (G-series, $F(-4), F(-3)$, and $F(-2)$ ). As with the performance test, the heat pipe units are expected to follow the sonic limit curve during part of the startup transient until thermal coupling between the calorimeter and the heat pipe condenser becomes the controlling heat transfer mechanism. Once this coupling limit is reached, performance will move off the sonic limit, transitioning across the operating envelope as power and temperature increase to the final steady-state conditions. A typical startup transient is estimated at approximately 1 to 2 hours, with the steady-state condition maintained for up to 6 months (the nominal inspection interval). The test setup makes use of an autonomous control/data system to monitor operations and recording test data. In the event of power outages/facility interruptions or heat pipe temperature, power or pressure excursions this control system will shut down and safe the operation. 


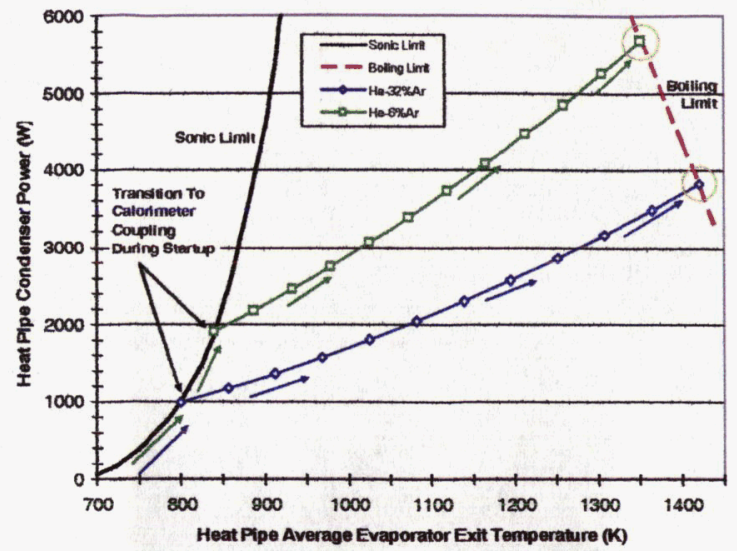

FIGURE 5. Heat Pipe Performance Test Predictions.

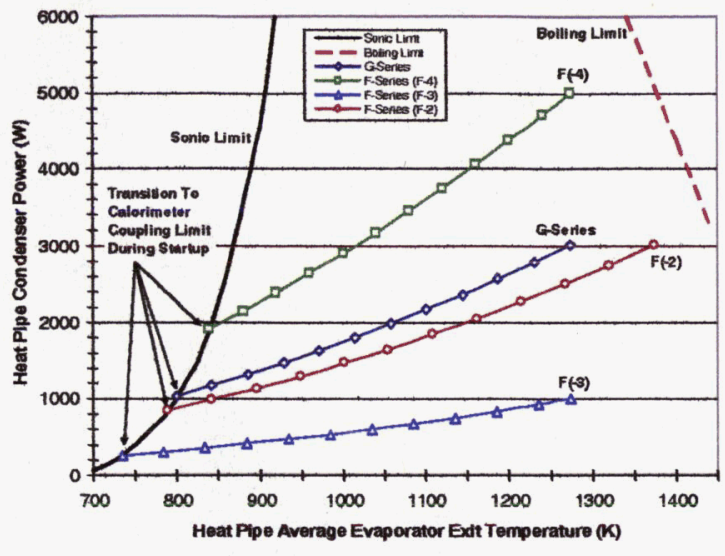

FIGURE 6. Heat Pipe Startup Transient and Accelerated Life Test Operational Predictions.

Planned heat pipe accelerated life testing is broken into approximate 6-month intervals. This allows for a combination of non-destructive and destructive evaluations (NDE/DE) to be performed. The first planned inspection will be of the as-fabricated heat pipes prior to test to provide a baseline. The current planned method for NDE will make use of a 3-D X-Ray tomography method (such as HYTEC Inc. hardware). To accurately compare data collected from the heat pipe units throughout the three years of expected testing, two or more fiducials shall be placed on each unit. This will allow for accurate alignment of $\mathrm{x}$-ray images taken at each inspection interval so that changes can be readily interpreted. Possible locations for these fiducials are the evaporator and fill stem plugs. The HYTEC inspection has a native resolution of 0.004 inches $(0.01 \mathrm{~cm})$. To achieve the maximum possible resolution with molybdenum rhenium alloys, the voltage would need to be increased and exposure time extended to enable measurement of working fluid distributions and distortions on the of order $<0.002$ inches $(0.005 \mathrm{~cm})$. Figure 7 illustrates a sample HYTEC analysis for a stainless steel heat pipe mesh wick used in the SAFE-30 heat pipes (Van Dyke, 2003). This wick has a diameter of approximately $2.22 \mathrm{~cm}$ and is composed of $400 \times 400$ mesh wire with a diameter of $0.025 \mathrm{~mm}$ (resolution in this examination approaches 0.004 inches).
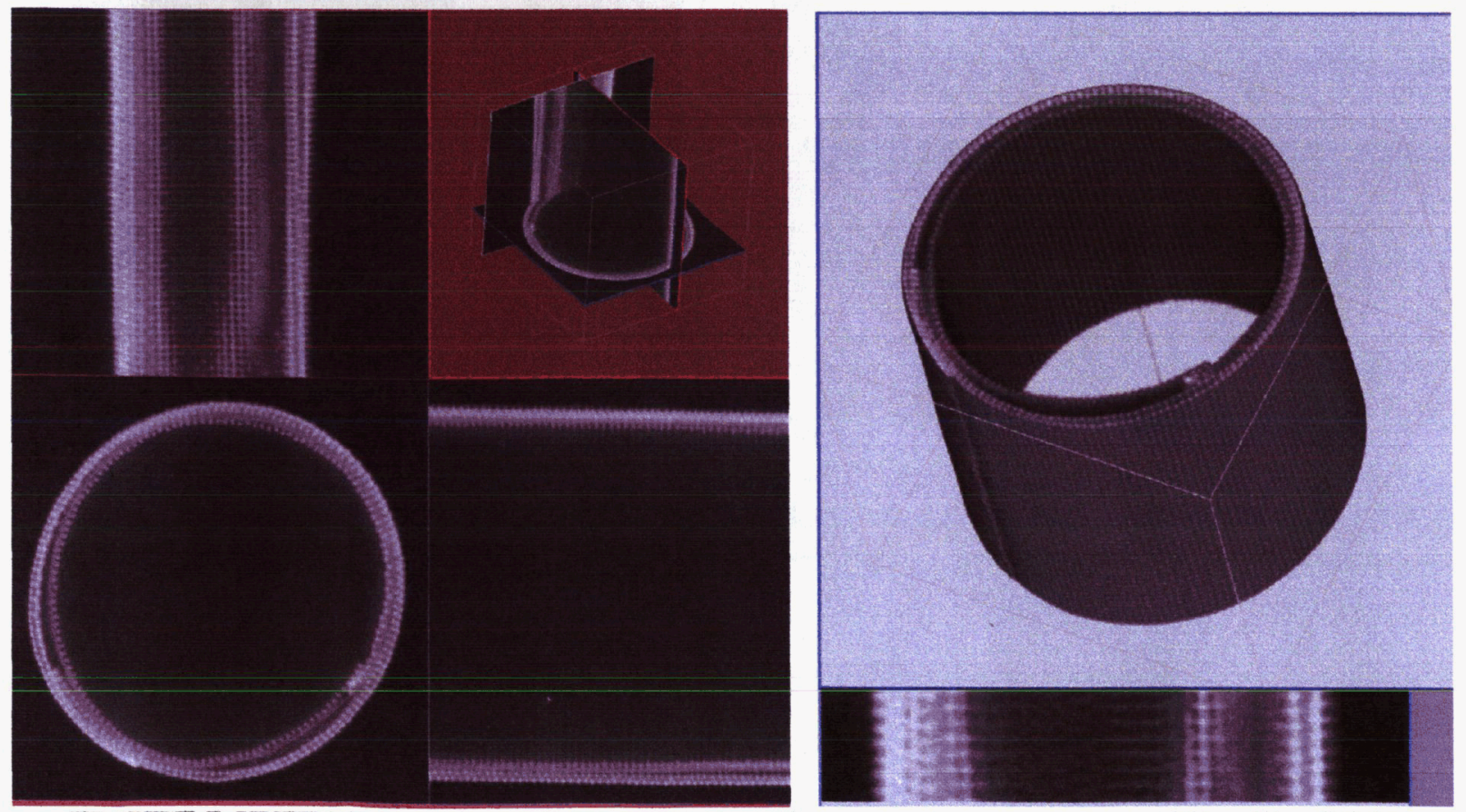

FIGURE 7. HYTEC Tomographic Examination of SAFE-30 Composite Stainless Steel Heat Pipe Wick. 


\section{SUMMARY}

The proposed Mo-Re/Na heat pipe design and test matrix systematically addresses the issues related to corrosion rates at operating temperatures anticipated for space nuclear operations. Data could be expected to be produced early in the program (within 6 months of starting the first heat pipe), providing early indications of the aging effect. Additional data obtained over the course of the planned 3-year operation builds confidence in extrapolations and provides insight into possible random manufacturing and processing defects. Power throughput covers a range from 1000 to $5000 \mathrm{~W}$ with planned operating times up to 3 years; temperatures range from $1173 \mathrm{~K}$ to $1373 \mathrm{~K}$. Performance testing of the initial heat pipes will be necessary to determine if the high power/temperature conditions in the test matrix can be achieved. If boiling limits are exceeded, test matrix adjustments will be made to appropriately lower power/temperature conditions. The heat pipes are shortened versions of a flight prototype to minimize program cost. The pipes were arranged in clusters to minimize the number of test chambers and ancillary equipment and cost required for this dedicated program. Radio frequency heating was chosen as the method to power the heat pipe evaporators requiring a number of series inductors that operate below voltage breakdown limits. To absorb energy from the heat pipe condenser a non-sealed static gas gap/laminar flow water calorimeter concept appears feasible. The initial analysis of the coupling gas purity indicates that the oxygen level $(\mathrm{ppb})$ within the test chamber can be reduced to a level consistent with that normally achieved under vacuum testing conditions $\left(10^{-6}\right.$ torr range) typically used for Mo-Re alloys. The use of commercial purifier systems further reduces the impurity level below that achieved by successive dilutions. Test chamber(s) environment can be monitored with a residual gas analyzer. Autonomous systems to monitor and control all processes regarding round the clock heat pipe test operation have been outlined and are ready for implementation. Additionally, significant progress was made related to fabrication of an annular wick structure. This wick was fabricated from Mo-5\%Re screen material (existing NASA stock) by a hot isostatic pressing (HIP) technique producing a final product with a maximum pore radius of 22 microns while retaining ductility. Execution of the accelerated heat pipe life test project was terminated due to a shift in program direction and as a result efforts have been redirected.

\section{NOMENCLATURE}

$\begin{array}{lll}\mathrm{d}_{\mathrm{o}} & = & \text { heat pipe diameter }(\mathrm{m}) \\ A & = & \text { heat pipe channel width }(\mathrm{cm}) \\ d & = & \text { heat pipe diameter outside }(\mathrm{m}) \\ D_{i} & = & \text { heat pipe inside diameter }(\mathrm{m}) \\ G & = & \text { mass flux }\left(\mathrm{kg} / \mathrm{cm}^{2}-\mathrm{sec}\right) \\ h_{\mathrm{fg}} & = & \text { latent heat of vaporization }(\mathrm{J} / \mathrm{kg}) \\ \Delta H & = & \text { activation energy }(\mathrm{J} / \mathrm{mole}) \\ k & = & \text { thermal conductivity }(\mathrm{W} / \mathrm{m}-\mathrm{K}) \\ L_{a} & = & \text { adiabatic length }(\mathrm{cm}) \\ L_{c} & = & \text { heat pipe condenser length }(\mathrm{cm}) \\ L_{e} & = & \text { heat pipe evaporator length }(\mathrm{cm}) \\ M^{\prime \prime} & = & \text { mass fluence }\left(\mathrm{kg} / \mathrm{cm}^{2}\right) \\ q & = & \text { applied evaporator power }(\mathrm{W}) \\ q_{\text {rad }} & = & \text { radial heat flux }\left(\mathrm{W} / \mathrm{cm}^{2}\right) \\ Q & = & \text { design heat pipe power }(\mathrm{W}) \\ r & = & \text { wick pore radius }(\text { micron) } \\ R & = & \text { universal gas constant }(\mathrm{J} / \mathrm{mole}-\mathrm{K}) \\ T & = & \text { temperature }(\mathrm{K}) \\ \left.T_{0}\right) & = & \text { design temperature }(\mathrm{K}) \\ \alpha(T) & = & \text { normalized Arrhenius diffusion rate } \\ \tau & = & \text { time (sec) }\end{array}$




\section{ACKNOWLEDGMENTS}

The authors thank members of the Marshall Space Flight Center's team for their support in this effort: Eric Stewart, Robert Hickman, Shannon Bragg-Sitton and Kenneth Webster. NASA's Project Prometheus supported the work described within this paper, in whole or part, as part of the program's technology development and evaluation activities. Any opinions expressed are those of the author(s) and do not necessarily reflect the views of Project Prometheus.

\section{REFERENCES}

ASTM International, “Standard Practice for Liquid Sodium Corrosion Testing of Metals and Alloys," ASTM G 68-80.

ASTM International, "Standard Test Methods for Chemical and Instrumental Analysis of Nuclear-Grade Sodium and Cover Gas," ASTM C 997-83.

Deming, S. N. and Morgan, S. L., Experimental Design: A Chemometric Approach (Elsevier, New York, 1987).

Dickenson, T. J., Woloshun, K. A., and Stoyanof, M., "Microgravity Experiment of Three Liquid Metal Heat Pipes," Proc. 10" Int. Heat Pipe Conf., Stuttgart, Germany (1997).

Feber, R. C. and Merrigan, M. A., "Thermochemical Modeling of Mass Transport in High-Temperature Heat Pipes," Proc. VI Int. Heat Pipe Conf., Grenoble, France (1987).

Loeb, L. B., Fundamental processes of Electrical Discharges in Gases, John Wiley and Sons, Inc., New York, 1939.

Lundberg, L. B., "Alkali Heat Pipe Corrosion Phenomena," Proc. VI Int. Heat Pipe Conf., Grenoble, France (1987).

Park J., Henins I., Herrmann, H., and Selwyn G., "Gas Breakdown in an Atmospheric Pressure Radio-Frequency Capacitive Plasma Source", Journal of applied Physics, Vol. 89, No. 1, January, 2001, pp 15-19.

Reid, R. S. "Heat Pipe Transient Response Approximation," Proc. Space Technology and Applications International Forum (STAIF 2002), Albuquerque, NM AIP Conf. Proc. (2002).

Reid, R. S., "Alkali Metal Heat Pipe Life Issues," in Proceedings of International Congress on Advanced Nuclear Power Plants (ICAPP-2004), Conf Proceedings Published by ANS, Pittsburgh, PA, Paper 4291, 2004, pp 2319-2329.

Sena, J. T., and Merrigan, M. A., "Niobium 1\% Zirconium Potassium and Titanium Potassium Life-Test Heat Pipe Design and Testing," in M. S. El-Genk and M. D. Hoover, ed., Proceedings of the Seventh Symposium on Space Nuclear Power Systems, Albuquerque, NM, 1990, CONF-900109.

Van Dyke, M.K., Martin, J.J. and Houts, M.G., Overview of Nonnuclear Testing of the Safe, Affordable 30-kW Fission Engine Including End to End Demonstrator Testing, NASA/TM-2003-212930.

Weston, G. F., "Glow-Discharge Characteristics of Helium-Argon Mixtures", British Journal of Applied Physics, Vol. 11, July, 1960, pp 305-306.

Woloshun, K. A., Merrigan, M. A., and Best, E. B., "HTPIPE: A Steady-State Heat Pipe Analysis Program." LA-11324-M, Los Alamos National Laboratory, Los Alamos, 1988. 